\title{
Energy modeling/Simulation Using the BIM technology in the Curriculum of Architectural and Construction Engineering and Management
}

\section{Dr. Hyunjoo Kim, The University of North Carolina at Charlotte}

Assistant Professor of Engineering Technology and Construction Management He has 10 years of work experience in the construction fields and six years in research and teaching. His research interests include the use of 3D/BIM (Building Information Modeling) technology for energy modeling and simulations, information technology support for project management, artificial intelligence, data mining, machine learning, and advanced infrastructure systems. Research interests: - Construction Engineering-Project Management $\bullet$ Sustainability (Green Building Design and Construction) $\bullet$ Energy Modeling and Simulations • Building Information Modeling (BIM) • Data Mining (DM) and Analysis 


\title{
DATA ANALYSIS IN BIM (BUILDING INFORMATION MODELING) \\ Case Study - Energy Modeling/Simulation
}

\begin{abstract}
As building information modeling (BIM) gains appreciation in the industry, its promise to transform the traditional building design and construction process is being recognized. Building information modeling offers the promise of a common information repository for all project participants. In order to fully utilize the technology in the construction industry, this paper identified a need for developing a new educational approach in increasing productivity and collaboration in the Architectural, Engineering, Construction and Facilities Management (A/E/C \& FM) industry. With BIM as a digital representation of information developed and associated with all the building components, this paper describes how to utilize the data stored in a BIM with an example of energy analysis and modeling and illustrates how to utilize the information stored in BIM.
\end{abstract}

Keywords: Data Analysis, Knowledge, Information, Energy Estimates/Modeling, Building Information Modeling (BIM)

\section{INTRODUCTION}

The Architectural, Engineering, Construction and Facilities Management (A/E/C \& FM) industry is beginning to appreciate that technology can transform the building design and construction process with the increasing interest in the form of building information modeling (BIM). Increasingly, there have been many real applications reporting successes at applying BIM in the A/E/C industry. While there are various definitions of BIM in different applications, the paper emphasizes the need to recognize BIM as a digital representation of physical and functional characteristics of a facility and as a shared resource of knowledge about a project, thus forming a reliable basis for decisions to be made during its life-cycle, from inception and onward ${ }^{1}$. Thus, this paper intends to focus on how to make use of the digital representation of information developed and associated with all the building components in the school curriculum.

As the construction industry is adapting the BIM technology, computerized data are becoming more and more available. However, in most cases, these data might not be properly utilized. Several reasons exist: (1) complexity of the data analysis process is sometimes beyond the simple applications; and (2) there was no well-defined data analysis procedure to extract, analyze the data and summarize the results so that the site managers could use it. This paper implements a procedure as an example to show how it can utilize the vast amount of information stored in BIM. 


\section{A CHALLENGE IN BIM EDUCATION}

BIM is one of the latest software technologies being introduced in the AEC industry. With the BIM technology, a building can be represented in a complete model of objects with virtual 3D digital representations and attributes with enhanced interdisciplinary collaboration. BIM includes IFC model specification with the total number of 653 entities and numerous attributes associated with each object. At its most basic, BIM can be considered as an object-oriented database from which model drawings can be extrapolated where the BIM database contains detailed information at both the component and overall building level. It is all agreed that we can't say enough of the importance of BIM as a visualized tool. At the same time, it is also important to identify the necessary subjects in an educational curriculum to help students understand how to increase productivity and coordination using BIM especially in the area of data transaction and interoperability in the construction industry.

Figure 1 shows a class survey from a BIM class (CMET 4073) in the department of Engineering Technology and Construction Management, University of North Carolina at Charlotte where students were asked to answer the importance of BIM. Figure 1 reveals that 3D modeling/design is the most dominant application (21\%) among students. The figure also shows that the educational demand on BIM from students is getting broader in scope and includes various advanced subjects such as data management (13\%), conflict checking (21\%), coordination (13\%), and data exchange (8\%). Therefore, instructors nowadays face a challenge of how to embrace the demand of students who are interested not just in 3D modeling/design process but also in other subjects as shown in Figure 1.

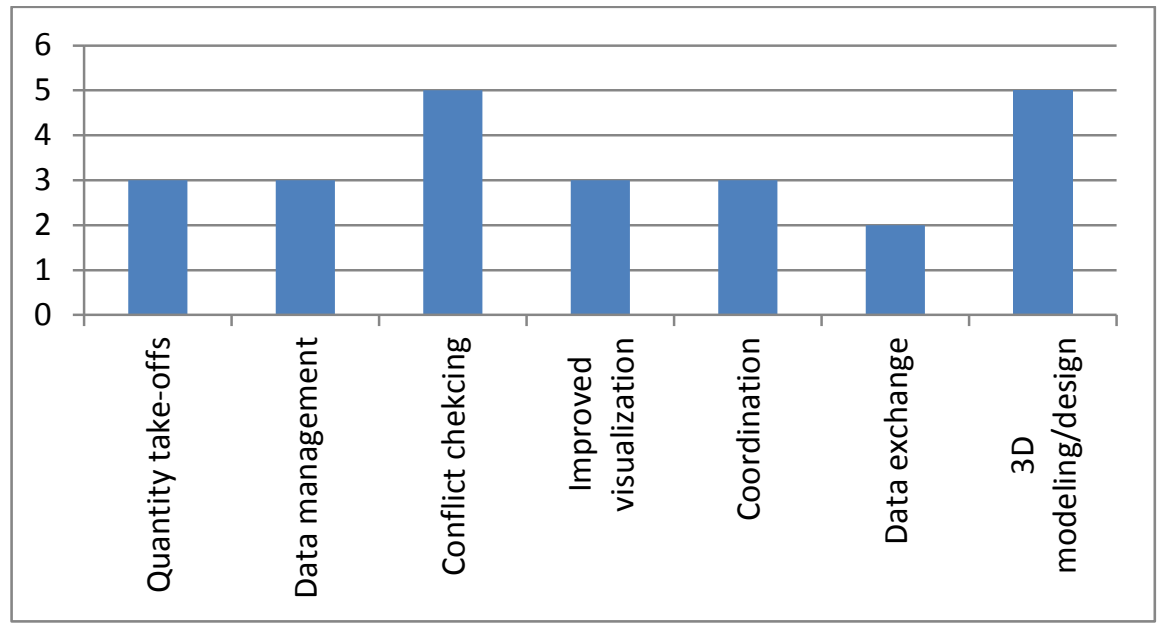

Figure 1. Understanding of BIM applications among students in CMET 4073, UNCC

Figure 1 also confirms the importance of utilizing data stored in BIM and shows that the students' interests in BIM who are enrolled in construction management program are evolving and shifting toward an area of data transactions such as data management, data exchange, conflict checking and so on. In another survey conducted in Spring 2013 where students were asked about BIM benefits, the most common response was "Improved productivity and better multiparty communication and understanding" (82\%) 
with improved safety (7\%), and positive impact on sustainability (9\%). School programs are definitely being helped by an increasing number of data and coordination oriented commercial programs (Solibri, COBie, DDS CAD and so on), BIM still remains a challenging task in school to adopt the various demands in an educational curriculum.

\section{EDUCATIONAL OBJECTIVES}

Most of the current education of BIM in school depends heavily on commercial products in 3D modeling, conflict checking, automatic scheduling, etc. while the potential benefits of data exchange and interoperability from BIM interoperability have been mostly ignored. The proposed course curriculum presents BIM as a model that stores all the tasks related to the actual modeling of the project, such as setting up levels, creating walls, doors, windows, floors, roofs, adding furniture, appliances, and fixtures. The paper intends to presents a course curriculum to utilize the computerized data stored in BIMs as well as simulation data generated in each data transaction and learn from the data by extracting, and identifying valid, useful, and previously unknown patterns. The specific BIM simulation to be demonstrated as a case study in this paper is energy modeling and simulation. From the author's experience, even a simple energy modeling run generated pages of data with many different variables. Examples of those variables include but are not limited to the estimated energy costs or savings in terms of building orientation, HVAC system, lighting efficiency and control, construction of roof and walls, glazing type, water usage, day-lighting, etc. Such volumes of data clearly overwhelm traditional data analysis methods such as spreadsheets and ad-hoc queries with so many factors to be considered. It is difficult to find the best correlation/combination of different energy systems during the building design process.

Building energy simulation programs are in use throughout the building energy community. Energy modeling programs provide users with key building performance indicators such as thermal loads, energy use and demand, temperature, humidity, and costs. As the $\mathrm{A} / \mathrm{E} / \mathrm{C}$ industry is embracing energy simulation programs, building designers are currently dealing with a large amount of data generated during the energy simulations. The specific learning objectives of the proposed course are for students to:

1. Understand the fundamentals of BIM (Building Information Modeling) and Energy Analysis.

2. Understand energy modeling process in BIM.

3. Demonstrate how data analysis process can be used in analyzing the data generated in BIM based energy simulation.

4. Understand data analysis techniques in data classification, prediction, and mining association rules.

5. Recognize the Green Design, Construction and implementation issues.

6. Analyze, evaluate, and recommend the data analysis process from the construction owners, contractors, and/or project managers’ perspectives 


\section{CASE STUDY}

To demonstrate the process of how knowledge (or interesting patterns) out of computerized BIM data, this paper shows a BIM based energy simulation/modeling process. An emerging trend in the $\mathrm{A} / \mathrm{E} / \mathrm{C}$ industry today is creating sustainable, high performance buildings. For the past 50 years, a wide variety of building energy simulation (BES) analysis tools have been developed, enhanced, and applied throughout the building energy community. However, many of the existing energy modeling tools are complex, text-based applications which require a great deal of time to $\operatorname{learn}^{2}$. On the other hand, a recent innovation in building design and construction, Building Information Modeling (BIM) has received tremendous interest for its impact on sustainable development and provides the opportunity to develop energy analysis software programs for the industry. More than just the lines and arcs associated with traditional computerassisted drawing (CAD) tools, BIM includes associated benefits of visualization, built-in intelligence and simulation, intelligent objects of a structure, such as spatial data (3D), unstructured data (text), and structured data (databases, spreadsheets). With the addition of building geometry data in a BIM, the volume can be calculated and energy estimates made based on building envelope characteristics (doors and windows) and building orientation. In the proposed course, the following topics are to be included:

1. Preparing a BIM in Autodesk MEP

2. Energy Modeling in Green Building Studio

3. Data analysis in classification, association, clustering, and regression

4. Identifying a noble pattern through data analysis

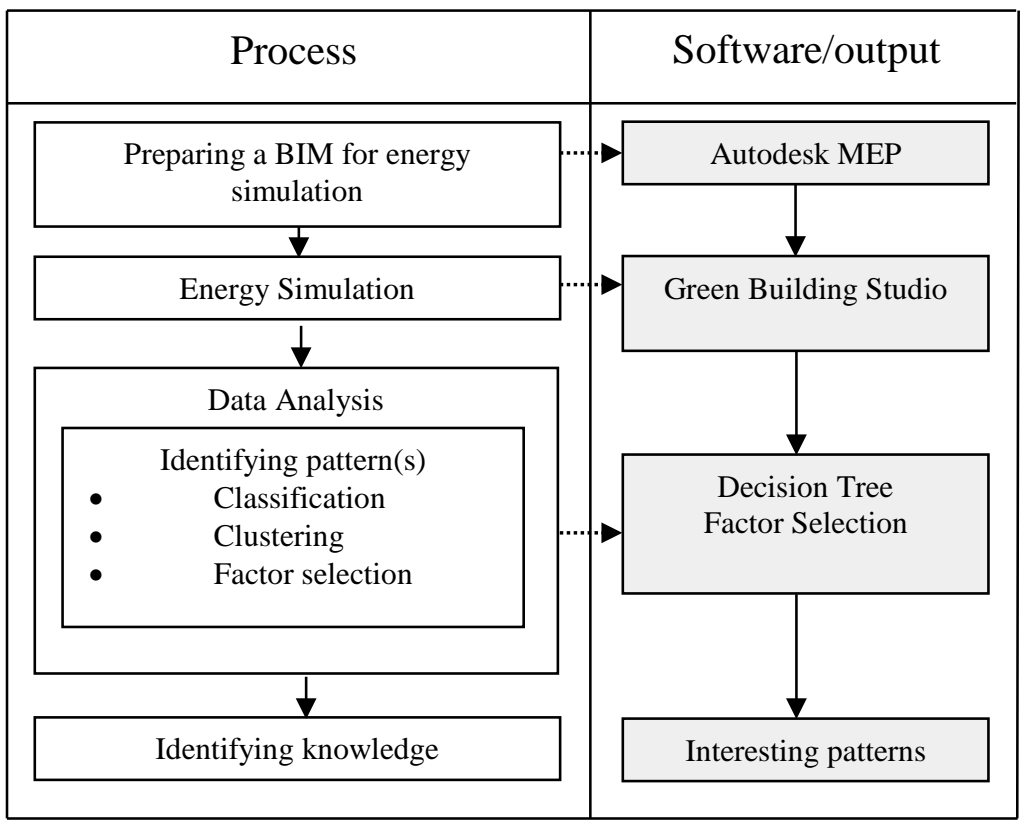

Figure 2. Data Analysis in BIM based energy simulation 


\section{Data Analysis Process}

The goal of the data analysis is to develop an overall data analysis process that can be applied to find patterns for energy-related behaviors of a construction project. During the data analysis, data analysis tools are exploited to extract and identify noble patters. Data analysis methods have been applied to problems such as learning to drive an autonomous vehicle, learning to recognize human speech, learning to detect credit card fraud, and learning strategies for game playing. The data analysis tools include inductive inference of decision trees, neural network learning, statistical learning methods, genetic algorithms, Bayesian methods, explanation-based learning, and reinforcement learning. Some of the important data analysis tools are factor selection in calculating the relevance of features, and Decision Tree to extract useful patterns. When comparing different building components and equipment, all the energy costs are estimated and presented in dollars or electricity consumption $(\mathrm{kWh})$ throughout the data analysis.

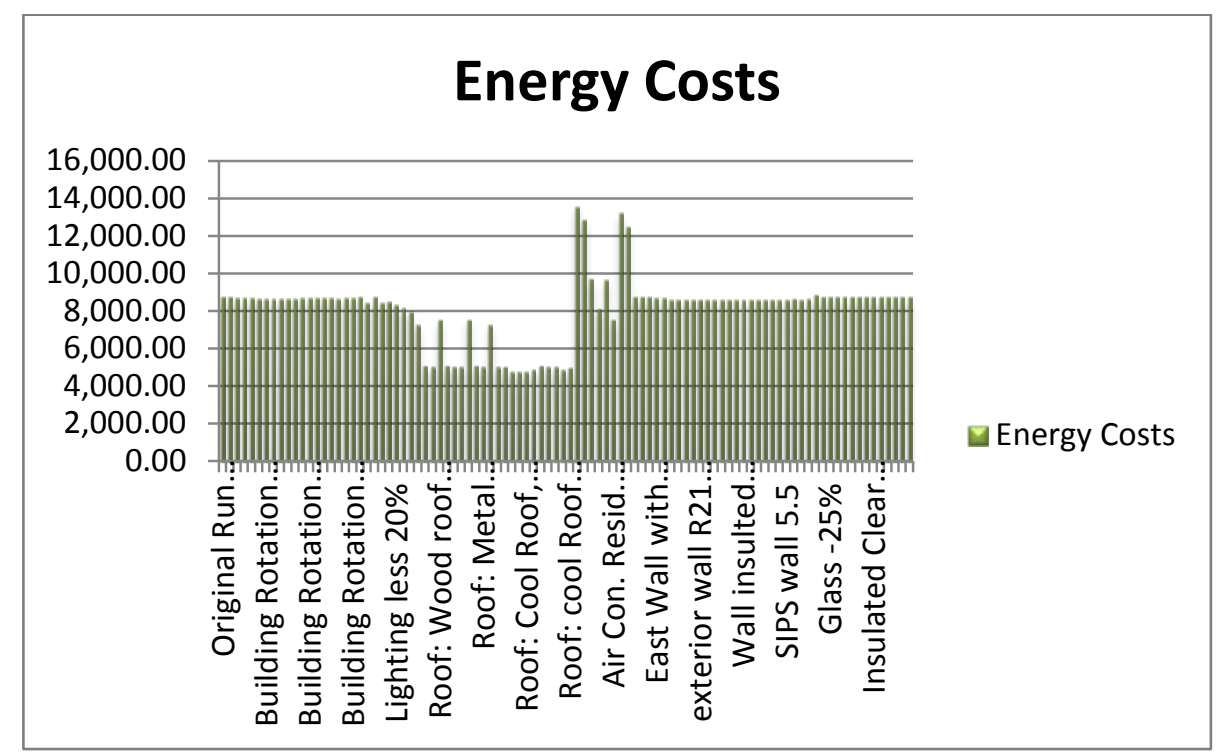

Figure 3. Energy estimates produced during BIM energy modeling process

\begin{tabular}{|c|c|c|c|c|c|c|c|c|c|c|c|c|c|c|}
\hline \multirow[b]{2}{*}{ Climate Zone } & \multirow{2}{*}{$\begin{array}{c}\text { HDD } \\
\text { (Base 65 F) }\end{array}$} & \multirow{2}{*}{\begin{tabular}{c|} 
CoD \\
(Base55 F)
\end{tabular}} & \multirow{2}{*}{$\begin{array}{l}\text { Ave. Temp. } \\
\text { Year Round }\end{array}$} & \multirow{2}{*}{$\begin{array}{l}\text { Av. Lowest } \\
\text { Temp/Year }\end{array}$} & \multirow{2}{*}{$\begin{array}{l}\text { Av. Highest } \\
\text { Temp/Year }\end{array}$} & \multirow{2}{*}{$\begin{array}{l}\text { AV. Highest } \\
\text { Month }\end{array}$} & \multirow{2}{*}{$\begin{array}{l}\text { AV. Lowest } \\
\text { Month }\end{array}$} & \multirow[b]{2}{*}{ Location } & \multirow{2}{*}{\begin{tabular}{|c|}
$\begin{array}{c}\text { Estimated } \\
\text { Energy Cost }\end{array}$ \\
Baseline \\
\end{tabular}} & \multirow{2}{*}{$\begin{array}{c}(<10,000 \text { Low } \\
)(10,000-13,000 \\
\text { Middle)(P13,000 } \\
\text { High) }\end{array}$} & \multicolumn{2}{|c|}{ Unit Energy Cost } & \multirow{2}{*}{$\begin{array}{l}\text { Distance to } \\
\text { major port }\end{array}$} & \multirow{2}{*}{$\begin{array}{c}\text { Climate } \\
\text { Zone }\end{array}$} \\
\hline & & & & & & & & & & & $\begin{array}{c}\text { Electric } \\
/ \mathrm{KWh}\end{array}$ & \begin{tabular}{|c|} 
Fuel(Gas)/ \\
Therm
\end{tabular} & & \\
\hline Miami, fl & 200 & 9474 & 76.70 & 69.10 & 84.2 & 90.90 & 59.60 & $1 \mathrm{~A}$ & $\$ 8,595,00$ & Low & so.13 & $\$ 2.13$ & 27.9 & Tropical \\
\hline Houston, TXC & 1599 & 6876 & 68.20 & 58.20 & 79.4 & 93.60 & 41.20 & $2 A$ & $\$ 8,985.00$ & Low & 50.13 & $\$ 1.38$ & 360 & Temperate \\
\hline Phoenix, AZ & 1350 & 8425 & 72.80 & 61.10 & 84.5 & 104.20 & 43.40 & $2 B$ & $\$ 9,739.00$ & Low & $\$ 0.10$ & $\$ 1.75$ & 13.7 & Temperate \\
\hline Memphis, TN & 3082 & 5467 & 62.30 & 52.50 & 72.10 & 92.10 & 31.30 & $3 \mathrm{~A}$ & $\$ 9,744.00$ & Low & $\$ 0.09$ & $\$ 1.44$ & 384 & Arid \\
\hline El Paso, TX & 2708 & 5488 & 64.70 & 52.10 & 77.10 & 95.30 & 32.90 & 3в & $\$ 11,746,00$ & Middle & $\$ 0.13$ & $\$ 1.38$ & 692 & Arid \\
\hline San Francisco, CA & 3016 & 2883 & 57.30 & 49.60 & 65.10 & 72.70 & 42.90 & $3 c$ & $\$ 8,862.00$ & Low & $\$ 0.14$ & $\$ 1.27$ & 18.4 & Temperate \\
\hline Baltimore, MD & 4707 & 3709 & 54.60 & 44.20 & 65.10 & 76.50 & 23.50 & $4 A$ & $\$ 15,437.00$ & High & $\$ 0.15$ & $\$ 1.61$ & 0.6 & Temperate \\
\hline Albuquerque, NM & 4425 & 3908 & 56.80 & 43.20 & 70.40 & 92.30 & 23.80 & $4 B$ & $\$ 12,744.00$ & Middle & $\$ 0.10$ & $\$ 1.23$ & 799 & Arid \\
\hline Seattle, WA & 4908 & 1823 & 52.80 & 44.80 & 59.80 & 75.60 & 35.00 & $4 C$ & $\$ 10,818.00$ & Middle & 50.08 & $\$ 1.31$ & 5 & Temperate \\
\hline Chicago, II & 6563 & 2941 & 49.10 & 39.80 & 58.30 & 83.50 & 14.30 & $S A$ & $\$ 13,409.00$ & High & $\$ 0.12$ & $\$ 1.21$ & 5 & Continental \\
\hline Colorado Springs, Co & 6415 & 2312 & 47.80 & 33.70 & 61.80 & 84.40 & 14.50 & $5 B$ & $\$ 13,038.00$ & High & 50.09 & so.s8 & 964 & Arid \\
\hline Burlington, VA & 7771 & 2228 & 45.20 & 35.80 & 54.50 & 81.40 & 9.30 & $6 A$ & $\$ 21,595.00$ & High & $\$ 0.15$ & $\$ 1.83$ & 257 & Continental \\
\hline Helena, MT & 7699 & 1841 & 44.00 & 31.20 & 58.70 & 83.40 & 9.90 & 68 & $\$ 15,805.00$ & High & $\$ 0.09$ & $\$ 1.15$ & 588 & Arid \\
\hline Duluth, MN & 9818 & 1536 & 39.10 & 29.30 & 48.70 & 76.30 & -1.20 & $7 \mathrm{~A}$ & $\$ 14,869.00$ & High & $\$ 0.10$ & $\$ 1.13$ & 3.8 & Continental \\
\hline Fairbanks, AK & 1390 & 1040 & 26.70 & 16.20 & 37.30 & 73.00 & -19.00 & $8 \mathrm{~A}$ & $\$ 13,199.00$ & High & $\$ 0.17$ & s0.87 & 363 & Continental \\
\hline \multicolumn{15}{|l|}{ Note: } \\
\hline \multicolumn{3}{|c|}{ Highest and Lowest Temprature were taken from: } & \multicolumn{3}{|c|}{ http: $: /$ wwnw.average-temperature.com/ } & & & & & & & & & \\
\hline Unit Energy Cost: & & & From "Green 8 & uilding Studio" & Results & & & & & & & & & \\
\hline
\end{tabular}

Figure 4. Different energy estimates in 15 different climate zones 


\section{- Feature subset selection.}

The technique of feature subset selection is used to find which building elements (windows, walls, doors, roofs and HVAC systems) are most likely to improve energy efficiency significantly. The feature subset selection algorithm conducts a search for a good subset using the induction algorithm as part of the evaluation function. The accuracy of the induced classifiers is estimated using accuracy estimation techniques. There are several induction algorithms ${ }^{3,4}$. According to the result shown in Figure 5, it is found that HDD (heating degree days), CDD (cooling degree days) and gas unit cost (price per Therm) were the most important factors in determining annual energy cost. And roof design and HVAC system are the second most important factors in reducing annual energy costs for our residential model.

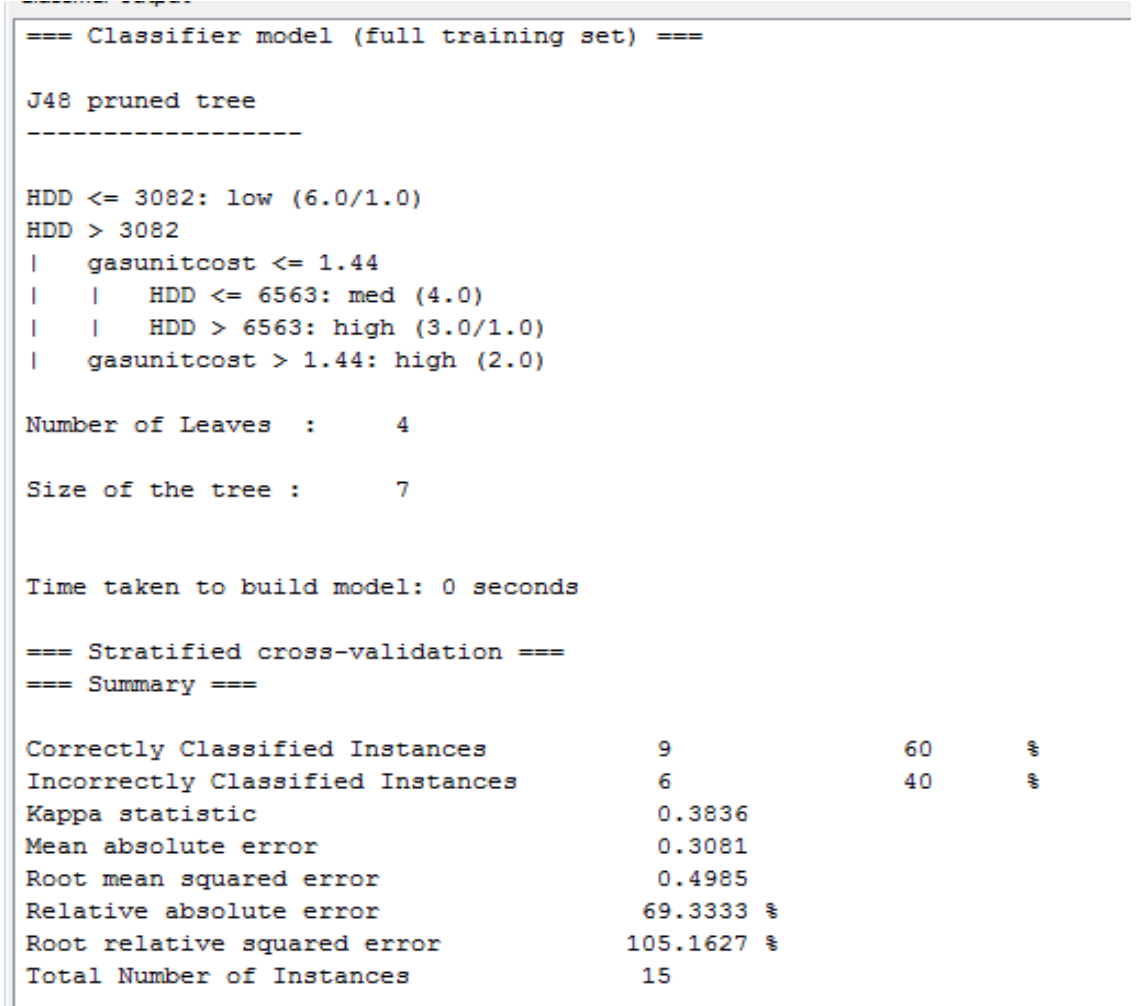

Figure 5. Factor selection result in energy estimates

\section{- Decision Tree}

Decision tree induction has been applied to many different applications as a simple and yet most successful form of a machine learning algorithm. There is much ongoing research on decision tree induction. For example, decision tree induction has been developed in a number of applications such as fraud detection ${ }^{5}$, marketing ${ }^{6,7}$, health care ${ }^{8}$ and portfolio analysis ${ }^{9}$. There are a number of decision tree and rule induction algorithms described in the machine learning literature ${ }^{3,10}$. A well known greedy tree growing algorithm for generating decision trees is Quinlan's ID3 with an extended version, called C $4.5^{3}$. C4.5 is currently one of the most commonly used data analysis algorithms, and is available in many commercial data mining products. The ease of its interpretability as 
well as its methods for dealing with numeric attributes, missing values, noisy data, and generating rules from trees make it a very good choice for practical classification. Once a decision tree or decision rule solution is generated from data, it can be used for identifying any interesting patterns out of the data or predicting the response or class variable for a new case. Figure 7 shows that the most important factors in improving energy efficiency are roof, HDD, CDD and HVAC systems.

\begin{tabular}{|c|c|c|}
\hline Glazing & Energy Estimate & Range \\
\hline wall & $\$ 22,591.00$ & high \\
\hline wall & $\$ 22,536.00$ & high \\
\hline wall & $\$ 22,555.00$ & high \\
\hline wall & $\$ 22,563.00$ & high \\
\hline wall & $\$ 22,651.00$ & high \\
\hline roof & $\$ 21,461.00$ & middle \\
\hline roof & $\$ 21,531.00$ & middle \\
\hline roof & $\$ 20,997.00$ & low \\
\hline roof & $\$ 21,461.00$ & middle \\
\hline rotation & $\$ 22,575.00$ & high \\
\hline rotation & $\$ 22,541.00$ & high \\
\hline rotation & $\$ 22,540.00$ & high \\
\hline rotation & $\$ 22,575.00$ & high \\
\hline rotation & $\$ 22,443.00$ & high \\
\hline HVAC & $\$ 20,782.00$ & Low \\
\hline HVAC & $\$ 22,251.00$ & High \\
\hline HVAC & $\$ 22,295.00$ & High \\
\hline HVAC & $\$ 22,086.00$ & High \\
\hline Lighting Efficiency & $\$ 20,720.00$ & Low \\
\hline Lighting Efficiency & $\$ 21,333.00$ & Middle \\
\hline Lighting Efficiency & $\$ 21,950.00$ & Middle \\
\hline Lighting Control & $\$ 22,448.00$ & High \\
\hline Lighting Control & $\$ 22,460.00$ & High \\
\hline Lighting Control & $\$ 22,551.00$ & High \\
\hline
\end{tabular}

Figure 6. Energy estimates used in Decision Tree data analysis

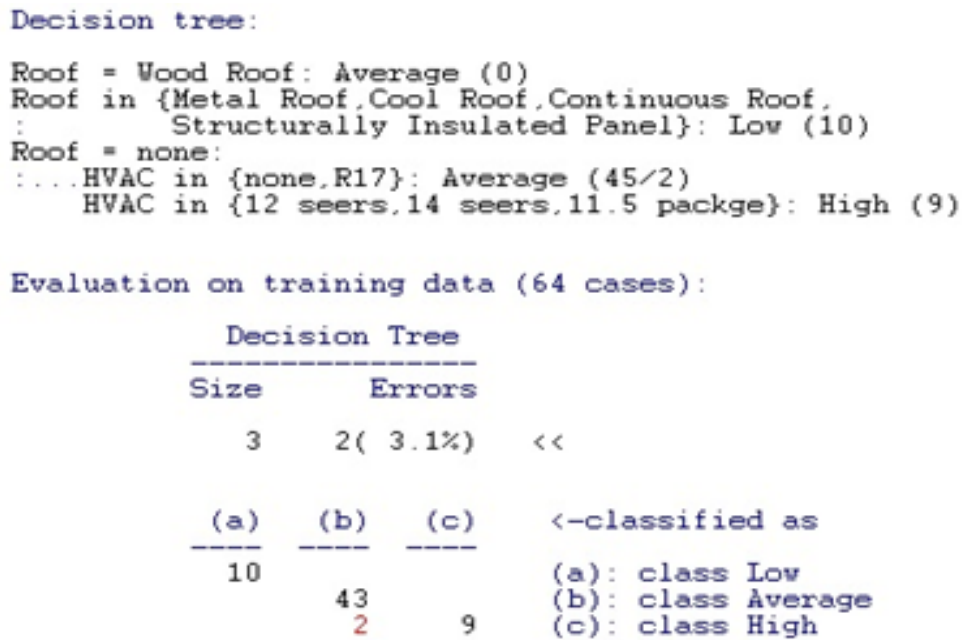

Figure 7. Decision Tree result 


\section{CONCLUSION}

Utilizing BIM-based energy modeling technology, this paper presented a data analysis procedure as an example to be used in a course where students may utilize BIM models in energy simulations, generate the results quickly and possibly identify an interesting pattern. The proposed course revealed that BIM based data analysis could 1) enable students to generate energy estimates easily and identify energy efficient options during the construction and 2) help students to understand what are the important factors in improving energy efficiency in a building construction. For example, students learned that improving the materials of roof, and HVAC is the most desired way to achieve high energy efficiency. Also they learned that building energy efficiency is most affected by climate factors such as HDD (heating degree days) and CDD (cooling degree days).

\section{REFERENCE}

1. buildingSMARTalliance (2007), “National BIM Standard 2007”, http://www.buildingsmartalliance.org

2. D. Crawley, J. Hand, M. Kummert, B. Griffith (2005), Contrasting the capabilities of building energy performance simulation programs, Joint Report Version 1.0.

3. R. Quinlan (1993), “C 4.5 Programs for Machine Learning”, Morgan Kaufmann Publishers, Inc.

4. P. Domingos, M. Pazzani (1997), “On the optimality of the simple Bayesian classifier under Zero-One loss”, Machine Learning.

5. Cox, K., Erick, S., Wills, G., and Brachman, R. (1997), "Visual Data Mining: Recognizing Telephone Calling Fraud", Data Mining and Knowledge Discovery.

6. Giannotti, F., Manco, G., Pedreschi, D. and Turini, F. (1999), "Experiences with a Logic-based knowledge discovery Support Environment", Proceedings of SIGMOD'99 Workshop on Research Issues on Data Mining and Knowledge Discovery, Philadelphia, PA, May

7. Thearling, K. (1995), "From Data Mining to Data Marketing".

8. Morishita, S., Hishiki, T., and Okubo, K. (1999), "Towards Mining Gene Expression Database", Proceedings of 1999 SIGMOD'99 Workshop on Research Issues on Data Mining and Knowledge Discovery, Philadelphia, PA, May

9. John, G., (1997), "Enhancements to the Data Mining Process", PhD Thesis, Computer Science Department, School of Engineering, Stanford University.

10. Breiman, L., Friedman, J. H., Olshen, R. A., and Stone, C. J. (1984). "Classification and Regression Trees", The Wadsworth Statistics/Probability Series, Belmont, CA 